\title{
Climate Change Impact on Rained Rice Production and Irrigation Water Requirement in Songkhram River Basin, Thailand
}

\author{
"S. Boonwicahi and S. Shrestha \\ Asian Institute of Technology, Pathumthani, Thailand \\ *Email: siriwatboonwichai@gmail.com
}

\begin{abstract}
Songkhram river basin, located in northeast Thailand, is where most of the farmers grow rice in rainy season. The water shortage frequently occurs during dry season as the basin has no dam along the river to store water for agriculture purposes. The river connected with Mekong River. Floods occur in many areas because high rainfall density in the basin and backwater effect from Mekong River. The climate change, temperature rise and uncertainty of rainfall, is significant influence to water availability for agriculture sector as well as agriculture production especially rice production. The study assesses the impact of climate change on irrigation water requirement (IWR) and rice production for KDML 105 rice variety in wet season (July - November) using DSSAT crop simulation model. The predicted of IWR and rice production were used an ensemble of five Regional Circulation Models (RCMs) under RCP4.5 and RCP8.5 scenarios for three future periods. The results show an increasing trend in both maximum and minimum temperature. The maximum and minimum temperatures are expected to rise up to $1.9{ }^{\circ} \mathrm{C}$ relative to baseline period (1980-2004) under RCP8.5 scenario in 2080s (2070-2094). Rainfall may decrease in the first future period, 2030s (2020 - 2044), and will rise in the 2055s (2045-2069) and 2080s (2070-2094) periods. Rainfall is projected to increase by $13 \%$ and $9 \%$ relative to baseline period for RCP4.5 and RCP 8.5 scenarios respectively in the last future periods (2080s). Therefore, the water shortage might occur in the first period. The middle and last periods might have flood due to higher of rainfall. The trend of IWR is expected to increase, which may rise by $18 \%$ and $5 \%$ in 2080s under RCP4.5 and RCP8.5 scenario respectively. Due to the increment of temperature and IWR, rainfed rice yield is found to decrease in the future. The rainfed rice yield may reduce by $14 \%$ and $10 \%$ for RCP4.5 and RCP8.5 scenario respectively in 2080s. However, the IWR is higher due to temperature rise in the future. The increasing of reservoir capacity and improve the water management practices might reduce the crop water deficit and increase crop production.
\end{abstract}

Indexed Terms- Climate change; Irrigation water requirement; Rice yield; Songkhram river basin.

\section{INTRODUCTION}

Thailand's agriculture is the large sector which contributed to $8.3 \%$ of Thailand's GDP in 2016 [1]. Rice production had the highest export value (172,241 million baht) in 2016 . Thailand was the world's largest rice producer and exporter. Thai jasmine rice (also known as "Thai Hom Mali rice" or "KDML105") is one of the main export products with high quality, which is grown mainly in the northeastern part of Thailand it has suitable growth under rain fed conditions (June to November) [2$3]$. 
Future climate is gradually changing. Global mean surface temperature could rise and precipitation would change depending on latitudes. Recent studies on future climate projections in Thailand have shown significant changes in temperature and rainfall. Thailand's temperature is expected to rise and precipitation might be higher and their patterns change in the future [4-7].

Climate change is likely to increase the world's water scarcity [8]. Temperature rise, likely increasing of amount of evaporation, combined with more uncertainty of rainfall have caused significant influence in irrigation water requirement [8-10]. Climate change could affect the future water availability worldwide. Recent studies such as those conducted by Fischer et al. (2007) [8], Silva et al. (2007) [9], Wang et al. (2012) [10] found that climate change significantly increases irrigation water requirement.

Climate is one of the most important factors of agriculture productivity [11]. Climate change could directly influence crop productivity since it is linked to physiological processes [12]. This issue could affect global food security especially in developing countries [13][10]. Climate change might have different impacts which include both positive and negative impacts, on quantity and quality of agricultural productions depending on location, climate zone, and crops [13][12][14]. Rice is one of the most important agricultural productions in the world. Arunrat and Pumijumnong (2015) [15], Babel et al. (2011) [16], Kuneepong et al. (2001) [17], and Pumijumnong and Arunrat (2013) [18] have studied the potential of climate change impact on rice production in Thailand. They concluded that the change of magnitude and pattern of temperature and rainfall could have impact on rice production.

Songkhram river basin (SRB) is more sensitive to the changing of climate on agriculture production. Most agriculture is grown during rainy season as the basin has no dam along the river to store water for agricultural purposes in other seasons. The changing of temperature and rainfall patterns has direct impacts on the agricultural sector in the basin. Since the water in Songkram river flows through the Mekong River, the water availability in the river is also dependent on the management of Mekong River in the upstream.

This study aims to assess the impact of climate change on rain fed rice (KDML 105 rice variety) production in Songkhram river basin, Thailand. The study projected the future climate used several Regional Circulation Models (RCMs) to address the uncertainties of climate models under two future climate scenarios (RCP4.5 and RCP8.5 scenarios). In addition, this study evaluated the future irrigation water requirement in case of temperature trends increasing, which means that the amount of evapotranspiration might be increased. Furthermore, appraisal of the potential impact on rice production from variability of climate and irrigation water requirement was done.

\section{MATERIALS AND METHODS}

\subsection{Study area}

Songkhram river basin is selected to study the impact of climate change on rainfed rice production and irrigation water requirement. The basin is the third largest tributary of the Mekong basin [19] and the second largest catchment in northeast Thailand [20] with a catchment area of approximately $12,700 \mathrm{~km} 2$. Songkhram river flows through parts of 5 provinces, approximately $420 \mathrm{~km}$ length, and flow through Mekong river at NakhonPhanom province. The basin receives higher amount of annual rainfall than other parts of Thailand, varies between $1200 \mathrm{~mm}$. and $2000 \mathrm{~mm}$. The average mean temperature varies from $21^{\circ} \mathrm{C}$ to $34^{\circ} \mathrm{C}$.

The topography in the basin is floodplain hence is suitable for paddy fields which approximately $68 \%$ of the basin land area. Most of the area consists of paddy fields, para rubber trees, 
and eucalyptus trees which takes up more than $90 \%$ of the agricultural land area in year 2010 . The household incomes earning mainly come from agriculture.

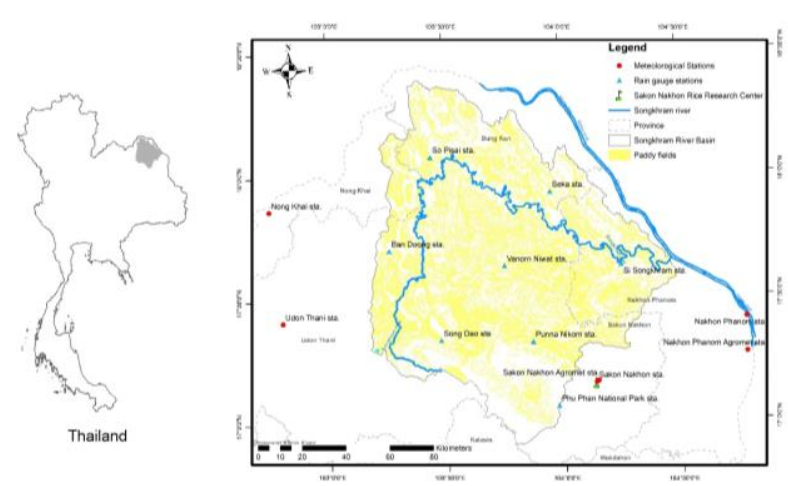

Figure 1: Location of the meteorological station, SakonNakhon Rice Research Center, and paddy fields for Songkhram river basin, northeast Thailand.

The variability of future climate has significant influence on people, water and agriculture sectors in Songkhram river basin since the main occupation depends on weather. Increasing of temperature and evaporation combined with uncertainty of rainfall have an effect on future water availability as the basin has no dams along the river to store water, and agricultural production as well as incomes.

\subsection{Data collection}

The weather data is measured by Thai Meteorological Department (TMD). The study used eight rainfall stations and six temperature stations to represent the weather in the basin. The daily weather data for period 1980-2015 used to project the future climate and generate the DSSAT crop simulation model.

Five Regional Circulation Models (RCMs) namely ACCESS1-CSIRO-CCAM, CNRM-CM5CSIRO-CCAM, HadGEM2-AO-MOHC-HadGEM3-RA, ICHEC-EC-EARTH-SMHI-RCA4, and MPI-ESM-LR-CSIRO-CCAM with $0.5^{\circ} \times 0.5^{\circ}$ resolutions were used for projecting future climate periods for three future periods; 2030s (2020-2044, 2050s (2045-2069), and 2080s (2070-2094) under RCP4.5 and RCP8.5 scenarios.

The study considered the rainfed KDML 105 rice variety. The paddy's field experiment and management practices were conducted by SakonNakhon Rice Research Center used to represent the paddy field management practices for the basin. In addition, Land Development Department (LDD) gathers information on soil property and characteristic.

The methodology to achieve the study's objective is project the future climate in the basin using five RCMs applied the Quantile Mapping method to bias correct the RCMs for baseline to project the future climate for three future periods $(2030 \mathrm{~s}, 2055 \mathrm{~s}$, and $2080 \mathrm{~s})$ under RCP4.5 and RCP8.5 scenarios. DSSAT crop simulation model was used to simulate the IWR and rice yield. The rice experimental data from SakonNakhon rice Research Center of year 2009-2011 was used to calibrate and year 2012-2013 used to validate the model.

\subsection{Climate change scenarios}

Regional Circulation Models (RCMs) are powerful tools for providing the future climate information for regional with small scale [21-22]. However, the individual climate model has different structures or parameter sets and contained errors from various sources [23-24]. Although RCMs are downscaled for specific area, they still feature systems errors [21]. Therefore, more RCMs are necessary to address the uncertainties of climate models [11][25]. 
The missing data can have significant effects on the results [26]. Hence, filling the missing value is the best option. The study filled the temperature's missing data by the linear interpolation method and APHRODITE's gridded data set for rainfall. Bias correction methods were used for reducing RCM error characteristics [21]. The Quantile Mapping technique [27-29] was applied for bias correction in this study. The QM technique is based on daily constructed empirical cumulative distribution functions (ecdfs). The QM technique could improve the median, variance, frequency, intensity and extremes [21]. In addition, the technique improves the frequency distributions shape, and the quality of original RCM [22]. The bias correction performance was evaluated using mean, standard deviation (SD), root mean square error (RMSE), and coefficient of determination $\left(\mathrm{R}^{2}\right)$.

\subsection{DSSAT crop simulation model}

The Decision Support System for Agrotechnology Transfer (DSSAT) crop simulation model version 4.6 was used to simulate the rainfed paddy growth and yield in the basin. DSSAT was developed by a consortium of US universities. DSSAT can simulate more than 42 crops which supported by data base management programs for soil weather, and crop management and experimental data [30-31]. DSSAT simulates the crop growth and yield based on morphological and physiological characteristics. Crop genetic information and carbon balance are mainly used to simulate crop growth and yield (Mishra et al., 2013)[25]. The model has been used for more than 20 years in over 100 countries worldwide. Many studies have used the model to simulate the rice yield with different places in Thailand [16][3233]. The study applied the DSSAT model to simulate the rainfed paddy field (KDML 105 rice variety). The crop model performance was evaluated using mean, root mean square error (RMSE), and coefficient of determination (R2).

\subsection{Simulation of future IWR and rice yield}

The ensemble corrected future climate variables were entered into the calibrated DSSAT crop simulation model to simulate the future IWR and rice yield under future climate scenarios for three future periods: 2030s, 2055s, and 2080s. FAO (1992) explained that the IWR could be calculated from the difference between the crop water need (ET) and the effective rainfall. The assumptions of this study are land use, soil characteristic, and crop management practices to be the same in the future.

\section{RESULTS AND DISCUSSIONS}

\subsection{DSSAT crop simulation model}

DSSAT crop simulation model version 4.6 was used in this study to simulate the rainfed paddy field for assessing the impact of climate change on rice irrigation water requirement and yield. There are three sets of minimum data required to run the model including weather data, soil data, and rice experiment and management practices data [30-31]. The model simulates crop growth and yield based on crop genetic coefficient information. Buddhaboon et al. (2004) [34] reported the genetic coefficient for the KDML10.

The study used four years' experimental data (2009-2012) to set up the model, hence, the results showed that the observed and simulated rice yield matched well. The crop model performance found that the model simulates the rice yield with coefficient of determination $\left(\mathrm{R}^{2}\right)$ value of 0.837 . The average observed yield is 1.959 ton/ha, and the average simulated yield is 1.918 ton/ha. The root mean square error (RMSE) is estimated as 0.009 ton/ha. In addition, the model validation simulated for two years (2013-2014) show that the average observed yield is $2.079 \mathrm{ton} / \mathrm{ha}$, and the average simulated yield is $2.071 \mathrm{ton} / \mathrm{ha}$. 
Table 1:Genetic coefficient for KDML105

\begin{tabular}{ccc}
\hline Genetic coefficient & Value & Description \\
\hline P1 & 502.3 & Basic vegetative phase of the plant \\
P2R & 1233.0 & Photoperiod sensitivity in panicle initiation \\
P5 & 386.5 & Grain filling duration \\
P2O & 12.7 & Critical photoperiod of development occurring at \\
maximum rate \\
G1 & 45.7 & Potential spikelet number coefficient \\
G2 & 0.0270 & Single grin weight \\
G3 & 1.00 & Tillering coefficient \\
G4 & 0.95 & Temperature tolerant coefficient \\
\hline
\end{tabular}

Irrigation water requirement (IWR) was calculated for Songkhram river basin using results from year 2009 to 2012 to represent the current IWR. FAO (1992) reported that the approximate paddy water requirement is $450-700 \mathrm{~mm}$ per cropping period. The simulated average effective rainfall during cropping period is estimated as $383 \mathrm{~mm}$. Therefore, the irrigation water requirement is at least $67 \mathrm{~mm}$ for baseline period.

\subsection{Future climate scenarios}

The average maximum temperature could increment with vary between $0.7^{\circ} \mathrm{C}$ and $1.1^{\circ} \mathrm{C}$ for $\mathrm{RCP} 4.5$ scenario, and between $0.7{ }^{\circ} \mathrm{C}$ and $1.9^{\circ} \mathrm{C}$ for RCP8.5 scenario. The magnitude of increment under RCP8.5 is higher than RCP 4.5. The peak of RCP 4.5 scenario might occur at middle period (2055s). In contrast, the maximum temperature is continually greater under RCP8.5 scenario, which could rise up to $1.9^{\circ} \mathrm{C}$ by the end of period (2080s) as shown in Table 2 and Figure 2.

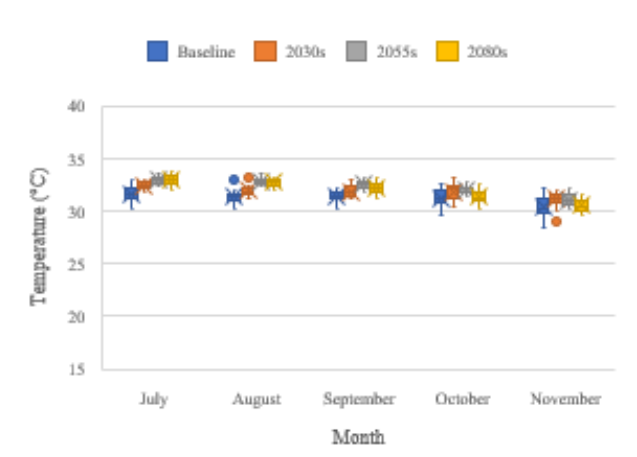

(a)

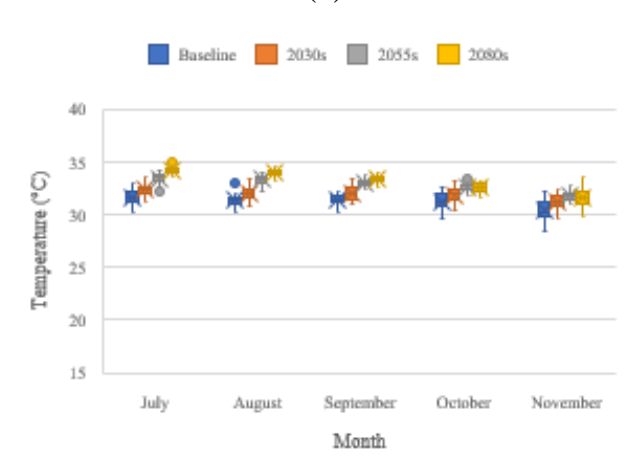

(b) 
Figure 2: Projected the average maximum temperature during rainfed rice period under (a) RCP4.5 and (b) RCP8.5 scenarios

Table 2: Change in maximum and minimum temperature, and rainfall during rainfed rice growing season (July-November).

\begin{tabular}{|c|c|c|c|c|c|c|c|}
\hline \multirow[b]{2}{*}{ Change in } & \multirow[b]{2}{*}{ Baseline } & \multicolumn{3}{|c|}{ rcp4.5 } & \multicolumn{3}{|c|}{ rcp8.5 } \\
\hline & & 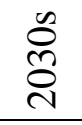 & $\begin{array}{l}n \\
\stackrel{n}{n} \\
\stackrel{n}{2}\end{array}$ & $\begin{array}{l}\infty \\
\infty \\
\infty\end{array}$ & 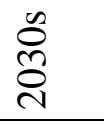 & $\begin{array}{l}n \\
\tilde{c} \\
\tilde{c}\end{array}$ & 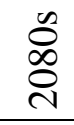 \\
\hline $\operatorname{Tmax}\left({ }^{\circ} \mathrm{C}\right)$ & 31.2 & 0.7 & 1.1 & 0.8 & 0.7 & 1.6 & 1.9 \\
\hline $\operatorname{Tmin}\left({ }^{\circ} \mathrm{C}\right)$ & 22.7 & 0.4 & 1.3 & 0.5 & 0.6 & 1.9 & 1.9 \\
\hline Rainfall (\%) & $827 \mathrm{~mm}$ & -17 & 15 & 11 & -13 & 12 & 9 \\
\hline
\end{tabular}

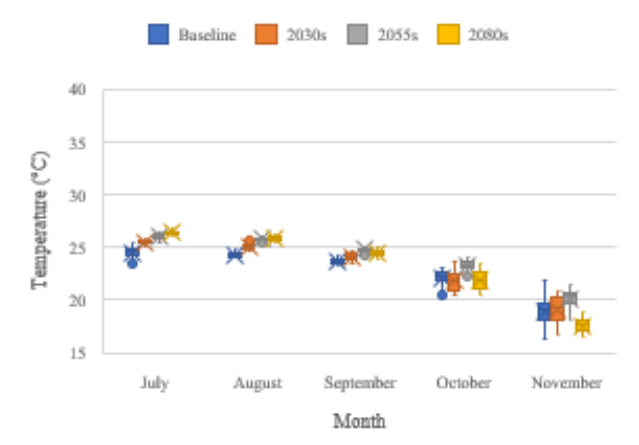

(a)

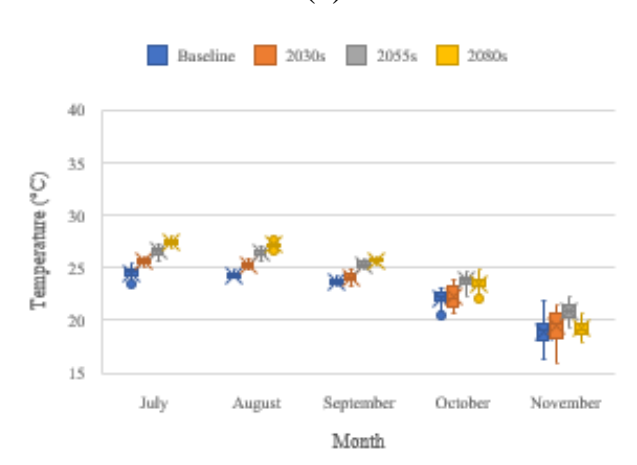

(b)

Figure 3: Projected the average minimum temperature during rainfed rice period under (a) RCP4.5 and (b) RCP8.5 scenarios

The average minimum temperature is expected to increase. It could vary between $0.4{ }^{\circ} \mathrm{C}$ and $1.3{ }^{\circ} \mathrm{C}$ for RCP4.5 scenario, and between $0.6^{\circ} \mathrm{C}$ and $1.9^{\circ} \mathrm{C}$ for RCP8.5 scenario. The peak could rise up to $1.3^{\circ} \mathrm{C}$ under RCP4.5 scenario at middle period $(2055 \mathrm{~s})$, and $1.9^{\circ} \mathrm{C}$ under RCP8.5 scenario for middle and last period (2055s and 2080s) as shown in Table2 and Figure 3.

The amount of rainfall during rainfed growing period might reduce in near period (2030s) for both scenarios. It could reduce by $17 \%$ from baseline. However, the amount of rainfall could increase in middle and last periods (2055s and 2080s). The middle period (2055s) could higher by $15 \%$ under RCP4.5 scenario, and $12 \%$ under RCP8.5 scenario. The rainfall could higher by $11 \%$ under RCP4.5 scenario, and $9 \%$ under RCP8.5 scenario for last period (2080s) as shown in Table2 and Figure 4.

Thailand's climate is gradually changing. The Thai Meteorological Department (TMD) reported that the historical average temperature is continuing rising, and rainfall has more variability and the trend is increasing. Future temperature and rainfall could increase. The recent studied 
supported the results of this study. Chinvanno and center, 2009; Chinvanno and Choengbunluesak, 2006; Bejranonda et al., 2010; Koontanakulvong et al., 2014 [4-6][35] concluded that future maximum and minimum temperature may rise in the future and rainfall may increase.

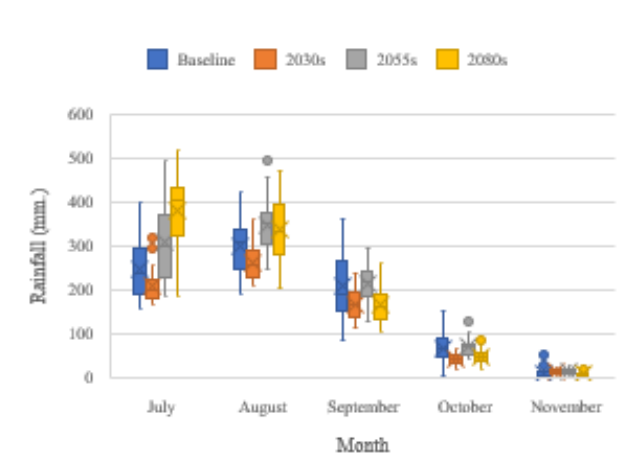

(a)

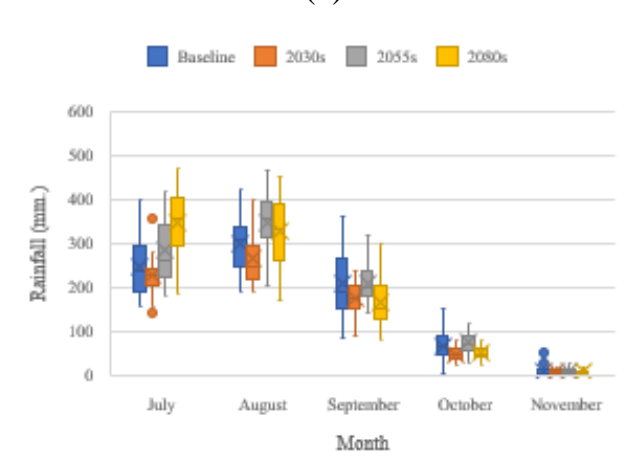

(b)

Figure 4: Projected the monthly rainfall during rainfed rice period under (a) RCP4.5 and (b) RCP8.5 scenarios

\subsection{Climate change impact on IWR and rice yield}

The calibrated DSSAT crop simulation model and ensemble of future climate data were used to estimate the future IWR and yield for three future periods under both RCP4.5 and RCP8.5 scenarios of rainfed rice season. The study considered the change of future climate (maximum and minimum temperature and rainfall), assumed, they are used the same crop management practices.

The results show that the average irrigation water requirement (IWR) is gradually higher. Temperature rise could increase the evaporation and transpiration which will also be influencing the IWR. The increasing of temperature and reducing of rainfall in first period (2030s) might increase the IWR between $2 \%$ and $7 \%$ under both climate scenarios. The water deficit might not occur in the second period $(2055 \mathrm{~s})$ with temperature rise and higher rainfall. On the other hand, the rise of temperature might increase the evaporation such that it might be severe enough to increase the IWR between $5 \%$ and $18 \%$ under both climate scenarios.

Recent studies presented that the changing of climate which increases temperature and change of rainfall pattern can significantly increase irrigation water requirement [8-10]. Rising of temperature might be the main reason to increase crop water requirement [10]. IWR is expected to increase in many countries due to climate change [36][8-10]. Silva et al. (2007) [9] reported that the paddy irrigation water requirement could increase by $23 \%$. However, mitigation could reduce the impact on it [8][37].

Climate change can significantly influence agricultural production [35][38-40]. Moreover, increasing of temperature and uncertainty of rainfall can reduce the crop yield [11][33][37-38]. Figure 5 shows that the trend of rainfed rice production is continually decreasing. In addition, the rice yield 
will increase by $7 \%$ in 2030 s and reduce by $10 \%$ and $14 \%$ for 2055 s and 2080 s respectively under RCP4.5 scenario. In contrast, the rice yield can decrease between $2 \%$ and $11 \%$ under RCP8.5 scenario. RCP 4.5 scenarios have gathered magnitude impact to reduce the rice production than RCP 8.5 scenario in last periods (2055s and 2080s). The magnitude impact of climate change on rice production depends on the varieties or cultivars used. Some cultivars might get the positive impact (increment yield) from climate change [33].

The impact of climate change on irrigation water requirement and rice yield for KDML 105 rice variety for wet season suggest that Climate change, change of temperature and rainfall, could affect the rice yield. The results show that temperature rise significant influent both direct and indirect on quantity of rice yield. Although water stress is not occurring in second period (2055s), the rice yield could decrease by temperature rise. In 2080s show that higher water deficit could reduce more in rice yield.

The future KDML 105's (photoperiod sensitive rice variety) rice production could reduce due to many factors that have significant influence to rice growth. The factors include temperature rise, reduce the sunshine hour, higher irrigation water requirement, and change in rainfall pattern. Temperature rise could affect many stages of rice grown such as decline in grain filling period, spikelet sterility, and losses during respiration which could reduce to quantity and quality of rice production [33].

The study considered only daily temperature, changing of night temperature might affect the rice production. In addition, since KDML 105 grown based on sun's light (photoperiod sensitive), growing of economic and social, the road's light at night might affect the rice growth and production.

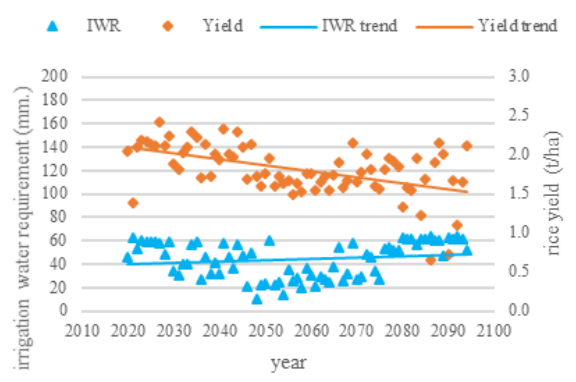

(a)

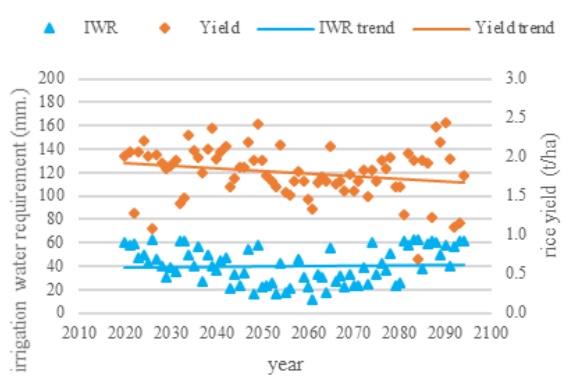

(b)

Figure 5: Trends of future rice yield and irrigation water management under (a) RCP4.5 and (b) RCP8.5 scenarios. 


\section{CONCLUSIONS}

The study assessed the possible impacts of climate change on irrigation water requirement (IWR) and rice production in Songkhram river basin, Thailand. DSSAT crop simulation model was used to simulate rainfed rice growth using an ensemble of five future climate models under RCP4.5 and RCP8.5 scenarios for three future periods (2030s, 2055s, and 2080s) relative to baseline period (19802004). The Quantile Mapping technique was applied for five RCMs to project the future climate in the basin.

The maximum and minimum temperatures, as well as rainfall are expected to increase. Future climate projections indicate that the maximum and minimum temperatures are expected to rise in the future for all future periods. The temperature is expected to rise up to $1.9^{\circ} \mathrm{C}$ by 2080 s relative to baseline period, the RCP8.5 scenario is expected to experience a higher magnitude of increment than RCP4.5 scenarios. The maximum temperature is expected to be $0.7-1.1{ }^{\circ} \mathrm{C}$ and $0.7-1.9{ }^{\circ} \mathrm{C}$ from 2030 s to 2080 s relative to baseline for RCP4.5 and RCP8.5 scenarios respectively. Similarly, minimum temperature is expected to rise by $0.4-1.3{ }^{\circ} \mathrm{C}$ and $0.6-1.9{ }^{\circ} \mathrm{C}$ from 2030 s to $2080 \mathrm{~s}$ relative to baseline for RCP4.5 and RCP8.5 scenarios respectively. In contrast, rainfall might decline in the first period (2030s) by $17 \%$ and $13 \%$ for RCP4.5 and RCP8.5 scenarios respectively. The rainfall might be greater in $2055 \mathrm{~s}$ and $2080 \mathrm{~s}$ by $11-15 \%$ and $9-12 \%$ relative to baseline for RCP4.5 and RCP8.5 scenarios.

The simulation of irrigation water requirement and yield of rainfed KDML 105 rice variety with future climate data suggests that the rainfed paddy field might experience water deficit issues in the future which have significant influence on the quantity of rice production. The water deficit issue might occur for the first and last future periods (2030s and 2080s). Although the annual rainfall is expected to increase in the future, the temperature rise is severe enough to increase the evaporation as well as crop water requirement. The water deficit might be higher by up to $18 \%$ relative to baseline for 2080s under RCP4.5 scenarios.

The rice yield might increase by $7 \%$ in 2030s for RCP4.5 scenarios; the climate condition might be suitable for rice growth. Furthermore, the rice yield continually declines by $10-14 \%$ from 2055 s to 2080 s for the RCP4.5 scenario. The rainfed rice yield might decrease by $2-11 \%$ relative to baseline from 2030s to 2080s for RCP8.5 scenario. Although results suggest that there is no water deficit issue in the $2055 \mathrm{~s}$, the temperature rise could also reduce the rice yield. The rice yield under RCP4.5 scenario creates a higher magnitude impact to reduce the future rice production because the RCP8.5 scenario has higher $\mathrm{CO} 2$ emission than RCP4.5 scenario which has positive impacts to rice growth. The results of this study might provide useful information which could be used by policy makers and stakeholders to manage the water during rainfed growing periods, and to optimize rice production under climate change scenarios in Songkhram river basin, Thailand.

\section{ACKNOWLEDGEMENTS}

The authors would like to thank Thai Meteorological Department (TMD), Land Development Department (LDD), and SakonNakhon Rice Research Center for providing the necessary data. 


\section{REFERENCES}

[1] Office of The National Economic and Social Development Board, 2017. Gross Domestic Product, Chain Volume Measures: Q1/2017. Thailand.

[2] Boling, A. A., Bouman, B. A. M., Tuong, T. P., Konboon, Y., \&Harnpichitvitaya, D. (2011). Yield gap analysis and the effect of nitrogen and water on photoperiod-sensitive Jasmine rice in north-east Thailand. NJAS-Wageningen Journal of Life Sciences, 58(1), 11-19.

[3] Limnirankul, B. and Gypmantasiri, P., 1998. Plant Genetic Resources Conservation and Development in Thailand: Food Crops.

[4] Bejranonda, W., \& Koch, M. (2010, March). Estimating future potential of KhlongYai reservoir using downscaling approaches: an assessment of climate change impact on water supply. In Proceedings of the 2nd regional conference on global environment: global environmental issues for sustainable development in the ASEAN region. Ho Chi Minh City, Vietnam.

[5] Chinvanno, S., \& Center, S. A. S. R. (2009). Future Climate Projection for Thailand and Surrounding Countries: Climate change scenario of 21 st century. Regional Assessments and Profiles of Climate Change Impacts and Adaptation in PRC, Thailand and Viet Nam: Biodiversity, Food Security, Water Resources and Rural Livelihoods in the GMS, 4.

[6] Chinvanno, S., \&Choengbunluesak, T. (2006). Final report on climate change scenarios for Songkram river basin. Southeast Asia START Regional Center, Bangkok, Thailand.

[7] Saraphirom, P., Wirojanagud, W., \&Srisuk, K. (2013). Impact of climate change on waterlogging and salinity distributions in HuaiKhamriansubwatershed, NE Thailand. Environmental earth sciences, 70(2), 887-900.

[8] Fischer, G., Tubiello, F. N., Van Velthuizen, H., \&Wiberg, D. A. (2007). Climate change impacts on irrigation water requirements: effects of mitigation, 1990-2080. Technological Forecasting and Social Change, 74(7), 1083-1107.

[9] Silva, D.C. S., Weatherhead, E. K., Knox, J. W., \& Rodriguez-Diaz, J. A. (2007). Predicting the impacts of climate change-A case study of paddy irrigation water requirements in Sri Lanka. Agricultural water management, 93(1), 19-29.

[10]Wang, W., Sun, F., Luo, Y., \&Xu, J. (2012). Changes of rice water demand and irrigation water requirement in Southeast China under future climate change. Procedia Engineering, 28, 341-345.

[11]Kang, Y., Khan, S., \& Ma, X. (2009). Climate change impacts on crop yield, crop water productivity and food security-A review. Progress in Natural Science, 19(12), 1665-1674.

[12]Deb, P., Shrestha, S., \& Babel, M. S. (2015). Forecasting climate change impacts and evaluation of adaptation options for maize cropping in the hilly terrain of Himalayas: Sikkim, India. Theoretical and Applied Climatology,121(3-4), 649-667.

[13]Bhattarai, M. D., Secchi, S., \&Schoof, J. (2017). Projecting corn and soybeans yields under climate change in a Corn Belt watershed. Agricultural Systems, 152, 90-99.

[14]Yamauchi, K. (2014). Climate change impacts on agriculture and irrigation in the Lower Mekong Basin. Paddy and water environment, 12(2), 227-240.

[15] Arunrat, N., \&Pumijumnong, N. (2015). The preliminary study of climate change impact on rice production and economic in Thailand. Asian Social Science, 11(15), 275.

[16] Babel, M. S., Agarwal, A., Swain, D. K., \&Herath, S. (2011). Evaluation of climate change impacts and adaptation measures for rice cultivation in Northeast Thailand. Climate Research, 46(2), 137-146

[17] Kuneepong, P., Kongton, S., Wangwachrakul, V., \&Sumdin, S. (2001, December). Modelling economic crop yield and climate change in Thailand. In ModSim 1. International Congress on Modelling and Simulation (pp. 10-13).

[18] Pumijumnong, N., \&Arunrat, N. (2013). Simulating the rice yield change in Thailand under SRES A2 and B2 scenarios with the EPIC model. Journal of Agri-Food and Applied Sciences, 1(4), 119-125. 
[19] Satrawaha, R., Prathepha, P., Andrews, R., \&Petney, T. (2009). Fundamental hydrochemical parameters of the Songkhram River in Northeast Thailand: foundation data for the study of an endangered tropical wetland ecosystem. Limnology, 10(1), 7.

[20] Blake, D., \&Pitakthepsombut, R. (2006). Situation Analysis: Lower Songkhram River Basin, Thailand. Mekong Wetlands Biodiversity Conservation and Sustainable Use Programme.

[21]Themeß1, M. J., A. Gobiet, and A. Leuprecht (2010), Empirical statistical downscaling and error correction of daily precipitation from regional climate models, Int. J. Climatol., doi:10.1002/joc.2168, in press.

[22] Themeß1, M.J., Gobiet, A. and Leuprecht, A. (2011). Empirical-statistical downscaling and error correction of daily precipitation from regional climate models. International Journal of Climatology, 31(10): 1530-1544.

[23] Ajami, N. K., Duan, Q., Gao, X., \&Sorooshian, S. (2006). Multimodel combination techniques for analysis of hydrological simulations: Application to distributed model intercomparison project results. Journal of Hydrometeorology, 7(4), 755-768.

[24] Shamseldin, A. Y., O'CONNOR, K. M., \& Nasr, A. E. (2007). A comparative study of three neural network forecast combination methods for simulated river flows of different rainfallrunoff models. Hydrological Sciences Journal,52(5), 896-916.

[25] Mishra, A., Singh, R., Raghuwanshi, N. S., Chatterjee, C., \&Froebrich, J. (2013). Spatial variability of climate change impacts on yield of rice and wheat in the Indian Ganga Basin. Science of the Total Environment, 468, S132-S138.

[26] Little, R. J., \& Rubin, D. B. (2014). Statistical analysis with missing data.John Wiley \& Sons.

[27] Chen, J., Brissette, F. P., Chaumont, D., \& Braun, M. (2013). Finding appropriate bias correction methods in downscaling precipitation for hydrologic impact studies over North America. Water Resources Research,49(7), 4187-4205.

[28] Madadgar, S., Moradkhani, H., \&Garen, D. (2012). Towards improved post-processing of hydrologic forecast ensembles. Hydrological Processes, DOI:10.1002.

[29] Teutschbein, C., \& Seibert, J. (2013). Is bias correction of regional climate model (RCM) simulations possible for non-stationary conditions?.Hydrology and Earth System Sciences, 17(12), 5061.

[30]Hoogenboom, G., J.W. Jones, P.W. Wilkens, C.H. Porter, K.J. Boote, L.A. Hunt, U. Singh, J.I. Lizaso, J.W. White, O. Uryasev, R. Ogoshi, J. Koo, V. Shelia, and G.Y. Tsuji. 2015. Decision Support System for Agrotechnology Transfer (DSSAT) Version 4.6 (http://dssat.net). DSSAT Foundation, Prosser, Washington.

[31] Jones, P. G., \& Thornton, P. K. (2003). The potential impacts of climate change on maize production in Africa and Latin America in 2055. Global environmental change, 13(1), 51-59.

[32] Buddhaboon, C., Kongton, S., \&Jintrawet, A. (2004). Climate scenario verification and impact on rainfed rice production. Report of APN CAPABLE Project. Southeast Asia START Regional Center, Chulalongkorn University, Bangkok.

[33] Shrestha, S., Chapagain, R., \& Babel, M. S. (2017). Quantifying the impact of climate change on crop yield and water footprint of rice in the Nam Oon Irrigation Project, Thailand. Science of The Total Environment, 599, 689-699.

[34] Tipparak, S., \&Aroonrungsikul, C. (2011). Effect of plant supplement on seed germination and seed vigor of KDML 105 rice variety. WarasanWitthayasatKaset.

[35] Koontanakulvong, S., Chaowiwat, W., \&Miyazato, T. (2014). Climate change's impact on irrigation system and farmers' response: a case study of the Plaichumpol Irrigation Project, Phitsanulok Province, Thailand. Paddy and Water Environment, 12(2), 241-254.

[36] Diaz, J. R., Weatherhead, E. K., Knox, J. W., \& Camacho, E. (2007). Climate change impacts on irrigation water requirements in the Guadalquivir river basin in Spain. Regional Environmental Change, 7(3), 149-159.

[37] Shrestha, S., Deb, P., \& Bui, T. T. T. (2016). Adaptation strategies for rice cultivation under climate change in Central Vietnam. Mitigation and adaptation strategies for global 
change, 21(1), 15-37.

[38] Mahato, A. (2014). Climate change and its impact on agriculture. International journal of scientific and research publications, 4(4), 1-6.

[39] Shrestha, S. (2014). Assessment of climate change impacts on irrigation water requirement and rice yield for Ngamoeyeik Irrigation Project in Myanmar. In Climate Change Impacts and Adaptation in Water Resources and Water Use Sectors (pp. 67-91). Springer International Publishing.

[40] Shrestha, S., \&Trang, B. T. T. (2015). Assessment of the climate-change impacts and evaluation of adaptation measures for paddy productivity in Quang Nam province, Vietnam. Paddy and water environment, 13(3), 241-253. 